\title{
UNAS NOTAS SOBRE EL PRÓLOGO DE LA HISTORIA DEL VALEROSO CABALLERO DON RODRIGO DE PEÑADURA
}

\section{SOME NOTES ON THE PREFACE OF HISTORIA DEL VALEROSO CABALLERO DON RODRIGO DE PEÑADURA}

\author{
Luis Miguel SuÁReZ \\ IES Ornia, La Bañeza (León)
}

\section{RESUMEN:}

Este trabajo analiza brevemente los aspectos literarios más importantes del prólogo de la Historia del valeroso caballero don Rodrigo de Peñadura, sátira política en forma de novela que imita el Quijote. Igualmente, a partir de los datos históricos que allí se apuntan trata de establecer una serie de conclusiones en torno al autor y a la publicación de la novela.

Palabras clave: Luis Arias de León, Historia del valeroso caballero don Rodrigo de Peñadura, prólogo, sátira política.

\section{ABSTRACT:}

This paper examines briefly the most important literary aspects of the preface to Historia del valeroso caballero don Rodrigo de Peñadura, political satire in the form of a novel that imitates the Quixote. Likewise, from the historical data pointed out there, it tries to establish a series of conclusions about the author and the publication of the novel.

Key words: Luis Arias de León, Historia del valeroso caballero don Rodrigo de Peñadura, preface, political satire.

Entre las imitaciones del Quijote que aparecen a lo largo de la primera mitad del siglo XIX, se cuentan una serie de novelas de corte político que se sirven del modelo cervantino para satirizar las ideas filosóficas de la Ilustración y la ideología liberal'1.

\footnotetext{
* Recibido: 22-07-2020 / Aceptado: 03-09-2020.

${ }^{1}$ A este grupo pertenecen títulos como El liberal en Cádiz, o aventuras del abate Zamponi (1814) de Fray Ramón Valvidares y Longo; Don Papís de Bobadilla, o sea defensa del cristianismo y crítica de la seudo-filosofía (1829) de Rafael Crespo; El Quijote del siglo XVIII o historia de la vida y hechos, aventuras y fazañas de Mr. Le-Grand (1836) de Juan Francisco Siñeriz o las Aventuras de Rústico Di-Mas de Quincoces (1844) de Trifón Muñoz y Soliva. Sobre esta literatura antiliberal, véanse los trabajos de Álvarez DE Miranda, P., «Sobre el 'quijotismo’
} 
Una de ellas es la que ahora nos ocupa, la Historia del valeroso caballero don Rodrigo de Peñadura, aparecida en Marsella en 1823 y firmada por Luis Arias de León. Ambientada durante el trienio liberal, tiene como protagonista a un hidalgo leonés, Don Rodrigo de Peñadura Carbajal y Zúñiga, que enloquece leyendo las obras de los filósofos ilustrados. Para alejarlo de sus libros, su ama y un labrador vecino suyo, de nombre Roque Zambullo, lo convencen para que viaje a Astorga a pasar una temporada con un sobrino canónigo, con la esperanza de que el cambio de aires le restituya la salud mental perdida. Finalmente, después de unos accidentados preparativos, partirá acompañado de Roque en lo que él toma como una empresa para extender las ideas liberales por aquellas tierras. En el camino le sucederán diversas aventuras y encuentros que recuerdan distintos episodios del Quijote.

La obra presenta, sin duda, no pocos aspectos de interés - por ejemplo, desde el punto de vista histórico y sociológico - , y un valor literario nada desdeñable, como ya señaló en su momento Cotarelo², que no encontramos en otras imitaciones del mismo género. Sin embargo, hay que señalar que apenas ha recibido la atención de la crítica. Aquí solo vamos a ocuparnos del prólogo, que a pesar de su brevedad resulta particularmente interesante, ya que en él se adelantan algunas características literarias de la novela y, además, se introducen una serie de datos que pueden ofrecer alguna pista sobre varios aspectos problemáticos relacionados con el autor y con la publicación del propio libro. Veamos su contenido, que transcribimos a continuación adaptando el texto a los usos ortográficos actuales:

\section{PRÓLOGO AL LECTOR}

Un tal M. Recherche, oficial del Estado Mayor del Príncipe de Hohenlhoe, hombre muy culto y en extremo aficionado a la literatura española, se hallaba en Burgos, a principios de mayo del año de 1823; y como de suyo era curioso y desease conocer los monumentos antiguos de aquella célebre ciudad, corte de los Reyes de Castilla, dirigió una tarde el paseo de sus meditaciones al emplazamiento en que existió, en otros tiempos, la población, admirando desde aquel punto la obra maestra de la arquitectura gótica, el elegante y simple arco de triunfo de Fernán González, y las bellas vistas que le ofrecía la campiña de las Huelgas.

Habiendo continuado en sus observaciones, se halló delante de un monumento modesto, que el patriotismo del Augusto Carlos III hizo levantar a la memoria del más valiente de todos los capitanes del mundo, y que por la inscripción que contenía conoció el oficial que se hallaba en el mismo sitio en que estuvo, en otra época, la casa solar del Cid.

dieciochesco y las imitaciones reaccionarias del 'Quijote' en el primer siglo XIX», en Dieciocho: Hispanic enlightenment, Vol. 27, № 1, 2004, págs. 31-46; y LóPEZ NAVIA, S. A, «La visión conservadora de Don Quijote en las recreaciones de la narrativa hispánica en el siglo XIX. Los rasgos de la filiación cervantina», en Strosetzki, Ch., Visiones y revisiones cervantinas: actas selectas del VII Congreso Internacional de la Asociación de Cervantistas, Alcalá de Henares, Centro de Estudios Cervantinos, 2011, p. 495-510.

${ }^{2}$ Discursos leídos ante la Real Academia Española en la recepción pública de D. Emilio Cotarelo y Mori el día 27 de mayo de 1900, Madrid, Imprenta Ducazcal, 1900, p. 18. 
A la memoria del Marte castellano, no pudo menos Recherche de pagar un justo tributo de admiración, derramando algunas lágrimas, producto noble de la simpatía de sus leales sentimientos con los de aquel inmortal guerrero.

Ya hacía media hora que se hallaba en aquel respetable terreno, cuando nuestro extranjero creyó descubrir unos papeles, que se hallaban al pie del Rollo. Pero, como de suyo era escudriñador y amigo de averiguar cómo pensaban los demás, los cogió, llevado de su curiosidad natural, y con admiración vio que estaban escritos en caracteres Mozárabes, lengua que le era absolutamente desconocida.

No obstante los dobló, y se los guardó en su faltriquera, con el firme propósito de mandarlos traducir, luego que se presentase la ocasión, por persona que fuese perita en el idioma Mozárabe.

Pero bueno será, amigo lector, que dejemos a M. Recherche ocupado en sus tareas militares, y que te haga saber que vuelto a su patria este oficial, concluida la campaña, desembarcó en Marsella, donde yo me hallaba a la sazón; y habiéndome conocido casualmente, enterado, no sé por quién, de que yo poseía el Mozárabe, pues había sido beneficiado en la capilla de los Reyes de Toledo, me entregó sus mamotretos, suplicándome encarecidamente los tradujese y diese a luz a la mayor brevedad.

Cuán grande fuese mi admiración, al ver que se trataba en aquellos borradores de las locuras que había hecho en este miserable mundo un paisano mío, no hay para qué pintarlo. Lo cierto es que cumplí con el encargo del propietario del manuscrito, y que él y yo quedamos satisfechos de la historia del héroe, deseando en Dios y en mi alma que a ti te suceda lo mismo.

El Licenciado LUIS ARIAS de LEÓN

Como se puede observar, el prólogo recrea el conocido tópico del manuscrito hallado. Arias de León marca ya desde el principio su inequívoco propósito de imitar el Quijote, con el que comparte igualmente, según aquí se nos adelanta, el esquema argumental, pues su historia trata también de las locuras de un héroe. Siguiendo el juego de la metaficción, se nos cuenta que un soldado francés, que formaba parte del contingente de los cien mil hijos de San Luis, halla en Burgos, junto al monumento del Cid, el original de la novela escrita en mozárabe y se la entrega al autor para que este la traduzca al español. Al modelo cervantino - o mejor dicho, a su parodia - se deben otros pormenores de este prólogo, que se pueden reconocer fácilmente. Así, el hecho incongruente de que el manuscrito esté en mozárabe no es sino un paralelismo paródico del manuscrito árabe de Cervantes. Por otra parte, la condición de antiguo beneficiado de la catedral de Toledo que se otorga el autor, además de servir para justificar su supuesto conocimiento - detalle de nuevo incoherente- de la lengua mozárabe, quizás implique también un guiño cervantino al hallazgo en la ciudad toledana de los cartapacios con el original de Cide Hamete Benengeli. Por lo demás, la impronta cervantina se extiende al nivel textual, ya que aquí resuenan, asimismo, ciertos ecos del Quijote. Nótese, por ejemplo, el paralelismo en la descripción del hallazgo del manuscrito en ambas novelas: 
...como de suyo era escudriñador y amigo de averiguar cómo pensaban los demás, los cogió, llevado de su curiosidad natural, y con admiración vio que estaban escritos en caracteres Mozárabes (Historia del valeroso caballero..., pp. 2-3).

...y como yo soy aficionado a leer aunque sean los papeles rotos de las calles, llevado desta mi natural inclinación tomé un cartapacio de los que el muchacho vendía y vile con caracteres que conocí ser arábigos (Quijote, I, 9).

Todos estos pormenores preludian una de las características esenciales de esta obra: su «directísima inspiración cervantina» ${ }^{3}$, una inspiración que se extenderá al esquema argumental, a los personajes, episodios, técnica literaria y lenguaje ${ }^{4}$.

Por otro lado, es de destacar que este prólogo desempeña una función estrictamente literaria. Y en esto difiere de los preámbulos de otras novelas de idéntico enfoque político, como, por ejemplo, El liberal en Cádiz (1814) o Don Papís de Bobadilla (1829). En estas últimas, sus autores aprovechan el prefacio para mostrar al lector su propósito ideológico, esto es, combatir las ideas ilustradas y defender el Altar y el Trono. Esta ausencia de elementos doctrinales explícitos preludia asimismo una notable virtud literaria de nuestra obra de la que no gozan las dos anteriormente citadas y otras del mismo género: «su capacidad para mantener un cierto pulso narrativo sin que este se vea ahogado por las digresiones apologéticas de índole filosófica, política o religiosa $»^{5}$. De esta forma, Arias de León, al liberarse de este lastre didáctico explícito tan característico de los modelos narrativos dieciochescos, presenta una propuesta narrativa que resulta, sin duda alguna, mucho más moderna.

Otro aspecto interesante que muestra el prólogo tiene que ver con la personalidad del propio autor. $Y$, es que, de nuevo en la estela cervantina, según hemos podido ver, este se asoma a estas páginas preliminares convertido en personaje para asumir su condición de mero traductor y editor del manuscrito de la novela. Y de sí mismo como personaje ofrece los siguientes datos: su nombre - licenciado Luis Arias de León-, su origen leonés, su condición de clérigo-«antiguo beneficiado de la catedral de Toledo», además - y su estancia en Marsella en el momento en que llega a sus manos el original. Está claro que algunos de estos detalles son ficticios y forman parte del juego novelesco. Así, ese nombre de Luis Arias de León no ha podido ser identificado

\footnotetext{
${ }^{3}$ Álvarez de Miranda, P., ob. cit., p. 38.

${ }^{4}$ Estos paralelismos son señalados por CotARELo, ob. cit.; MiñAmBRES, N., «Preliminar», en Arias de León, L.: Historia del valeroso caballero Don Rodrigo de Peñadura, León, Ediciones Leonesas, 1988, pp. v-xxxviii (xxiv-xxviiii); LóPEz NAviA, ob. cit.; y SuÁREZ, L. M., «Un Quijote leonés del siglo XIX: la Historia del valeroso caballero Don Rodrigo de Peñadura de Luis Arias de León», Argutorio, 40, 2018, págs. 47-54.
}

${ }^{5}$ ÁLVAREZ MirANDA, P., ob. cit., p. 39. Por lo demás, Arias de León muestra una clara oposición a las digresiones y al estilo ampuloso de los discursos, como puede observarse en el capítulo 3, cuando don Rodrigo revive, llevado por el ensueño, los tiempos de la batalla de Maratón y suelta un larguísimo discurso de seis páginas, en el que el autor se burla de su insufrible pedantería. 
hasta ahora y, por tanto, parece casi con toda seguridad un seudónimo ${ }^{6}$. En cambio, la estancia del autor en Marsella puede contener algún resquicio de verdad, pues allí se publica la obra. Respecto a su origen leonés - proclamado en la portada y reiterado en el prólogo - y a su condición de clérigo, aunque no hay luego en el libro detalles inequívocos que confirmen esas afirmaciones, pueden ser verosímiles, dicho sea con toda la cautela a la que esa falta de datos obliga. De lo que no queda ninguna duda es de la ideología antiliberal del autor. Esta circunstancia, unida a la aparición del volumen en Marsella y a las claras alusiones históricas a la entrada del ejército francés del duque de Angulema en España, parece relacionar a Arias de León con los realistas españoles avecinados en Francia. Ya Nicolás Miñambres señalaba que de ser cierta la noticia del lugar de publicación de la novela «habría que pensar en los frecuentes exilios políticos a la nación vecina a lo largo del primer cuarto de siglo»7. Álvarez de Miranda, por su parte, precisando más se preguntaba si no «sería su autor un "realista" refugiado en Francia, o trasladado allí para conspirar contra el régimen constitucional» $»^{8}$. Seguramente, este detalle podría explicar bien por qué este escritor, a pesar de la libertad de imprenta vigente en España que le hubiera permitido publicar el libro aquí, lo hizo en el país galo. Todo parece indicar, pues, que el novelista, si no estaba directamente comprometido con la causa absolutista, al menos algún vínculo debía de tener con los realistas, puesto que el libro es una sátira contra el trienio liberal y parece enmarcarse, por tanto, en el campo del combate político. En cualquier caso, prefirió ocultar su identidad, y ese hecho muy probablemente está relacionado con el contenido ideológico de la novela.

Otro aspecto del prólogo que merece nuestra atención son los llamativos detalles históricos con los que el autor adorna el relato del hallazgo del original de las aventuras de Peñadura, unos detalles que, según adelantábamos, pueden contribuir a esclarecer varios aspectos problemáticos relacionados con la publicación de la obra. Así, el hecho de que fuera publicada en Marsella ha suscitado extrañeza entre algunos críticos que han cuestionado la veracidad de su pie de imprenta ${ }^{9}$. Sin embargo, como ya

\footnotetext{
${ }^{6}$ Como apunta, Álvarez De MirandA, P., ob. cit., p. 37, no figura nadie así llamado en el completísimo Diccionario biográfico del Trienio Liberal dirigido por Alberto Gil Novales. Tampoco FERrERAS, J. I., Catálogo de novelas y novelistas españoles del siglo XIX, ob. cit., p. 48, pudo identificarlo. Como pone de manifiesto este catálogo y el libro del mismo autor, Los orígenes de la novela decimonónica, Madrid, Taurus, 1973, no son infrecuentes las obras del primer tercio del siglo XIX que aparecen firmadas con seudónimo.

${ }^{7}$ Ob. cit., p. v.

${ }^{8}$ Ob. cit., p. 38.

${ }^{9}$ Es el caso de Mancing, H., The Cervantes Enciclopedia: A-K. Vol. I, United States of America, Greenwood Press, 2004. Sin embargo, ya Álvarez DE MirandA, P., ob. cit., p. 38, señaló que «algunas características ortográficas y tipográficas del texto delatan que en efecto se imprimió al otro lado de los Pirineos» (aunque no precisó a qué características se refería).
} 
señalamos ${ }^{10}$, la impresión en Marsella está confirmada por dos importantes repertorios bibliográficos franceses: el Journal Général de la Littérature de la France y la Bibliographie de la France, ou Journal Général de l'Imprimerie et de la Librairie, que en la recopilación correspondiente al año 1824 consignan nuestro título en sus páginas ${ }^{11}$.

Asimismo, ha suscitado bastantes dudas la fecha de su publicación, ya que, aunque el volumen tiene pie de imprenta de 1823, fecha confirmada por el primero de los repertorios bibliográficos antes citados, la Bibliographie de la France (p. 149), algunos ejemplares parecen llevar fecha de 1824, lo cual plantea el problema de la existencia de dos ediciones. Ciertamente, esa circunstancia supondría, en primer lugar, que las aventuras del hidalgo leonés habrían alcanzado una difusión y un éxito notables, hasta el punto de agotar la primera edición e inducir a su autor a sacar una segunda. Este extremo, en principio, no parece muy probable, pues carecemos de datos que atestigüen esa buena acogida. Además, hay que tener en cuenta que el volumen se anuncia como tomo I - y de hecho, su último capítulo termina de forma abrupta - , lo que significa que el novelista parecía tener inicialmente el propósito de sacar un nuevo tomo, que continuara y tal vez completara las hazañas de su protagonista. No parece desde luego muy congruente que se reeditara el primer tomo de la historia de Peñadura sin haberla completado, cuestión esta última que resultaría lógica si el éxito de la primera parte hubiese sido tal.

En cualquier caso, es cierto que existen ejemplares que llevan fecha de 1824, pero resulta muy dudoso que se trate de una edición distinta ${ }^{12}$. De todas formas, el propio prólogo quizás nos ofrezca algunos datos que podrían explicar estas diferencias en las fechas de publicación de los ejemplares sin necesidad de recurrir a la existencia de dos ediciones. Y así, entre otras precisiones históricas que se reflejan aquí, se nos dice que el supuesto descubridor del manuscrito, $\mathrm{M}$. Recherche - nombre parlante y «una suerte de protohispanista», en palabras de Álvarez de Miranda ${ }^{13}-$, es oficial

\footnotetext{
${ }^{10}$ SUÁREZ, L. M., ob. cit.,_p. 47.

${ }^{11}$ Véanse respectivamente las páginas 150 y 149.

${ }^{12}$ Ferreras, J. I., en su catálogo de novelas del XIX, p. 48, no se mostraba taxativo, sin embargo, acerca de la existencia de esta segunda edición, y se limita a señalar lo siguiente: «Parece ser que existe otra edic. de iguales características en Marsella 1824, Impr. Carnaud y Simonin». Desde luego, es este un aspecto que requiere una investigación cuidadosa, que aún no se ha llevado a cabo. Así, habría que estudiar las características de estos ejemplares de 1824. Nosotros tenemos noticia al menos de dos: uno conservado en la Biblioteca de Castilla y León (signatura: g-41495) y otro en la BNE (signatura CERV/1144). El primero, en realidad, solo lleva la fecha de 1824 en la cubierta, ya que la portada tiene pie de imprenta de 1823 (vid. en línea http://bibliotecadigital.jcyl.es/es/catalogo_imagenes/grupo.cmd?path=10068183). Además, conserva la «Fe de erratas» de la primera edición y reproduce igualmente algunas erratas de esta (véase, por ejemplo, en la p. 91 una muy clara, lazón por lanzón). En cuanto al segundo, conserva la cubierta original, con fecha asimismo de 1824, y le faltan la portada y varias páginas del comienzo, pero parece en todo idéntico al anterior, por lo que parece tratarse de la misma edición (a su vez, como hemos dicho, idéntica a la primera).
} ${ }^{13}$ Ob. cit., p. 42, n. 18. 
del estado mayor del Príncipe de Hohenlohe, a cuyo mando está, en efecto, el Tercer Cuerpo del Ejército de los llamados Cien mil hijos de San Luis, que entraron en España en 7 de abril de 1823. Además, precisa que la visita del oficial a Burgos, donde hallará el manuscrito, se producirá «a principios de mayo del año de 1823». Conviene recordar que las tropas francesas que operaron en el Norte el año 23, fueron sobre todo las que formaban este tercer cuerpo de ejército al mando del Príncipe Luis de Hohenlohe, y que, efectivamente, para la fecha que se señala estaban ya en la ciudad de Burgos (en concreto desde el 23 de abril). De forma que el escritor, como parte del juego literario con el lector, ha rodeado el relato ficticio del hallazgo de la novela de una ambientación rigurosamente histórica.

Y continuando con el juego, se nos dice que M. Recherche, una vez concluida la campaña, desembarca en Marsella y se encuentra con nuestro autor, al que le entrega sus mamotretos para que «los tradujese y diese a luz a la mayor brevedad» ${ }^{14}$. Esa «campaña» solo puede referirse a la del ejército expedicionario francés, que oficialmente se da por concluida el 22 de noviembre de 1823, tras restituir en sus poderes absolutos a Fernando VII, que había entrado en Madrid el 13 de noviembre. De hecho, el duque de Angulema dará el 22 de noviembre su última orden general, que pone fin a su empresa restauradora, siete meses y medio después de haberla iniciado ${ }^{15}$, y un día después cruzaría el Bidasoa. Así pues, este dato en apariencia intrascendente nos está proporcionado, en realidad, el terminus post quem de la redacción del prólogo de la novela. En otras palabras, el prólogo de Arias de León nos sitúa, como muy pronto, a finales de 1823.

Por otro lado, no sabemos con exactitud cuándo entra el libro en la imprenta y cuándo se completa la tarea de impresión. Pero sí tenemos también, al menos, el terminus ante quem de su publicación: en la ya citada Bibliographie de la France nuestro volumen aparece en el boletín correspondiente al 6 de marzo de 1824, en el apartado «livres espagnols» (aunque con fecha, según hemos señalado, de 1823), lo cual quiere decir que había salido de las prensas, como poco, unas semanas antes, es decir, en febrero de 1824. De esta manera, todo apunta a que el proceso de publicación de la Historia del valeroso caballero don Rodrigo de Peñadura se produjo entre finales de 1823 y comienzos de 1824. De manera que es posible que incluso los primeros ejemplares fuesen tirados antes de que finalizara el año y la edición se completase ya en 1824, por

\footnotetext{
${ }^{14}$ Este detalle, por lo demás, constituye otro paralelismo con el episodio del hallazgo del manuscrito de Cide Hamete Benengeli, pues también, en el Quijote, el morisco aljamiado lleva a cabo con gran celeridad su tarea: «en poco más de mes y medio la tradujo toda» $(\mathrm{I}, 9)$.

${ }^{15}$ «Habiendo terminado felizmente la campaña, con la liberación del rey de España y la toma o sumisión de las plazas de su reino, hago constar el Ejercito de los Pirineos, al abandonarlo, mi más viva satisfacción por su celo...» (reproducida por LA PARRA, E., Los cien mil hijos de San Luis, Madrid, Síntesis, 2007, pp. 286-287).
} 
lo que el pie de imprenta divergente pueda obedecer, en realidad, a dos emisiones de una única edición. De hecho, los ejemplares de 1824 parecen en todo idénticos a los de 1823.

Por lo demás, que el libro aparezca en medio de ese convulso periodo de cambio político tal vez explique otros detalles a los que ya hemos aludido, como que no se publique el segundo tomo que completa las aventuras del hidalgo leonés. Y es que precisamente al ser una obra de combate ideológico, pierde su sentido, al menos inmediato, cuando los enemigos acaban de ser derrotados por las armas ${ }^{16}$. En cualquier caso, si Luis Arias de León es, como todo apunta, un seudónimo, parece claro que el verdadero autor no tuvo ningún interés por desvelar su identidad, aunque la nueva situación política sería propicia a ello, teniendo en cuenta que ya ninguna represalia podía temer de los liberales y que, por el contrario, una novela como la suya podría contribuir a otorgarle un incuestionable crédito político ${ }^{17}$. Claro está que también cabe la posibilidad de que el escritor quisiese llevar hasta el final el juego del autor apócrifo. $Y$, en fin, aún caben otras explicaciones. Pero eso, a falta de datos fidedignos, entra ya en el campo de la mera especulación.

En definitiva, el prólogo que figura al frente Historia del valeroso caballero don Rodrigo de Peñadura resulta enormemente sugestivo, pues puede proporcionar algunas claves sobre una novela rodeada de múltiples enigmas.

\section{BIBLIOGRAFÍA}

Álvarez Barrientos, J., «Introducción» a El liberal en Cádiz o Aventuras del abate Zamponi, Cádiz, Diputación, 2008

Álvarez De Miranda, P., «Sobre el "quijotismo" dieciochesco y las imitaciones reaccionarias del "Quijote" en el primer siglo XIX», Dieciocho: Hispanic enlightenment, Vol. 27, No 1, 2004, pp. 31-46.

\footnotetext{
${ }^{16}$ Algo semejante ocurrió con El liberal en Cádiz, novela del mismo cariz que la nuestra escrita por fray Ramón Valvidares y Longo, anunciada igualmente como «tomo primero» pero tampoco tuvo continuación, tal vez, como señala Álvarez Barrientos, porque la novela aparece en el preciso momento -1814- en que acaba la guerra, regresa Fernando VII al trono y acaba con los liberales, con lo que desaparecen los enemigos a los que pretende combatir. Véae Álvarez BARRIENTos, J.,«Introducción» a El liberal en Cádiz o Aventuras del abate Zamponi, Cádiz, Diputación, 2008, p. 43

${ }^{17}$ Resulta significativo que en la Gaceta del sábado 24 de diciembre de 1824 se anuncie la venta de El liberal en Cádiz, publicada diez años antes, según acabamos de señalar. Ciertamente, la nueva situación política era propicia para este tipo de literatura. De hecho se anunciaba con el siguiente reclamo: «cuyo objetivo es ridiculizar el sistema de los jacobinos». Por cierto, aunque en la princeps el escritor velaba su identidad bajo las iniciales F.V.R.,_ahora aparece con su nombre completo. También en La Gaceta, unos meses más tarde, el jueves 31 de marzo de 1825, se anunciaba nuestra novela, eso sí sin desvelar ningún detalle sobre su autor: «Historia de valeroso caballero D. Rodrigo de Peñadura. Publícala el licenciado Luis Arias de León, paisano del héroe. Un tomo en octavo. Véndese en La librería de Orea a 12 r[eale]s».
} 
Arias de León, L., Historia del valeroso caballero Don Rodrigo de Peñadura, Marsella, Imprenta de Carnaud y Simonin, 1823.

Bibliographie de la France, ou Journal Général de l'Imprimerie et de la Librairie, Paris, chez Pillet Ainé, 1824.

CotARelo y Mori, E., Discursos leídos ante la Real Academia Española en la recepción pública de D. Emilio Cotarelo y Mori el día 27 de mayo de 1900, Madrid, Imprenta Ducazcal, 1900.

Crespo, R., Don Papís de Bobadilla, o sea defensa del cristianismo y crítica de la seudo-filosofía, Zaragoza, Polo y Monge, 1829.

Ferreras, J. I., Los orígenes de la novela decimonónica, Madrid, Taurus, 1973 , Catálogo de novelas y novelistas españoles del siglo XIX, Madrid, Cátedra, 1979.

Journal Général de la Littérature de la France, vingt-septième année, Paris, Imprimerie de Marchand du Breuil, 1824.

La Parra, E., Los cien mil hijos de San Luis, Madrid, Síntesis, 2007.

López Navia, S. A., «La visión conservadora de Don Quijote en las recreaciones de la narrativa hispánica en el siglo XIX. Los rasgos de la filiación cervantina», en Strosetzki, Ch., Visiones y revisiones cervantinas: actas selectas del VII Congreso Internacional de la Asociación de Cervantistas, Alcalá de Henares, Centro de Estudios Cervantinos, 2011, pp. 495-510.

Mancing, H., The Cervantes Enciclopedia: A-K. Vol. I, United States of America, Greenwood Press, 2004.

MiÑAmbres, N., «Preliminar», en Arias de León, L.: Historia del valeroso caballero Don Rodrigo de Peñadura, León, Ediciones Leonesas, p. V-XXXVIII, 1988.

Muñoz y Soliva, T., Aventuras de Rústico Di-Mas de Quincoces, Madrid, Imprenta de José Félix Palacios, 1844.

SIÑERIZ, J. F., El Quijote del siglo XVIII o historia de la vida y hechos, aventuras y fazañas de Mr. Le-Grand, Madrid, Imprenta de D. Miguel de Burgos, 1836.

SuÁrez Martínez, L. M., «Un Quijote leonés del siglo XIX: la Historia del valeroso caballero Don Rodrigo de Peñadura de Luis Arias de León», Argutorio, 40, 2018, pp. 47-54. 